\title{
Doctors must not accept inducements for referrals, GMC says
}

Clarification-In this News story (BMJ 2015;350:h2098, doi:10. 1136/bmj.h2098), we said that a $B M J$ investigation published in January accused the GMC of taking no action after a leading healthcare insurer gave it a dossier of evidence showing that some consultants were taking inducements to refer patients to private facilities.

We should like to point out that after our investigation the GMC refuted these accusations. A spokesperson said that because the accusation related to "general concerns about incentives and referrals in private healthcare [and] did not include any allegations of wrongdoing relating to individual doctors," it had been unable to act. The GMC has no powers to carry out speculative industry wide inquiries to see what evidence of impaired fitness to practise it might find, the spokesperson explained.

Cite this as: BMJ 2015;350:h2167

๑ BMJ Publishing Group Ltd 2015 